\title{
Trends and future projections of the prevalence of adult obesity in Saudi Arabia, 1992-2022
}

A.J. Al-Quwaidhi, ${ }^{1}$ M.S. Pearce, ${ }^{2}$ J.A. Critchley, ${ }^{3}$ E. Sobngwi ${ }^{2}$ and M. O'Flaherty ${ }^{4}$

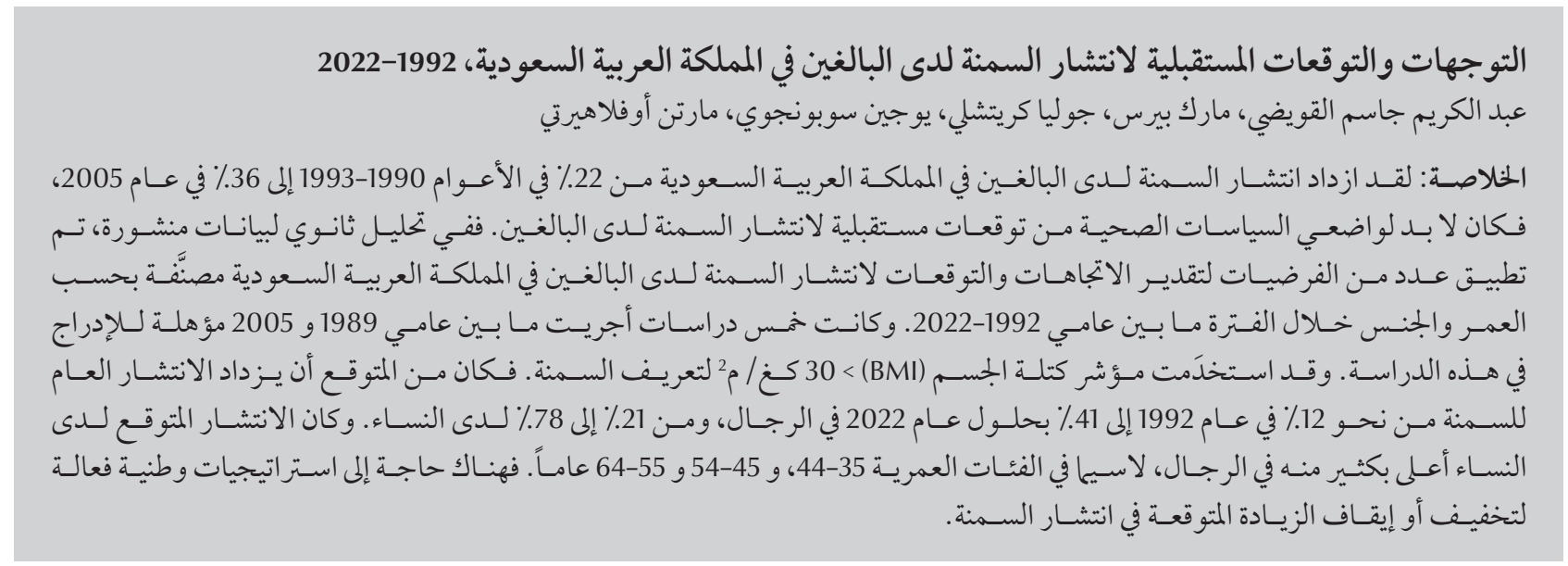

ABSTRACT The prevalence of obesity among adults in Saudi Arabia increased from 22\% in 1990-1993 to 36\% in 2005, and future projections of the prevalence of adult obesity are needed by health policy-makers. In a secondary analysis of published data, a number of assumptions were applied to estimate the trends and projections in the age-and sex-specific prevalence of adult obesity in Saudi Arabia over the period 1992-2022. Five studies conducted between 1989 and 2005 were eligible for inclusion, using body mass index (BMI) $\geq 30$ $\mathrm{kg} / \mathrm{m}^{2}$ to define obesity. The overall prevalence of obesity was projected to increase from around $12 \%$ in 1992 to $41 \%$ by 2022 in men, and from $21 \%$ to $78 \%$ in women. Women had much higher projected prevalence than men, particularly in the age groups 35-44, 45-54 and 55-64 years. Effective national strategies are needed to reduce or halt the projected rise in obesity prevalence.

\section{Tendances et projections de la prévalence de l'obésité chez l'adulte en Arabie saoudite, 1992-2022}

RÉSUMÉ La prévalence de l'obésité chez l'adulte en Arabie saoudite a augmenté, passant de 22 \% en 1990-1993 à 36 \% en 2005, et des projections de la prévalence de l'obésité chez l'adulte sont nécessaires pour les responsables de l'élaboration des politiques. Dans une analyse secondaire des données publiées, plusieurs hypothèses ont été appliquées pour estimer les tendances et les projections de la prévalence de l'obésité, spécifique à l'âge et au sexe, chez l'adulte en Arabie saoudite sur la période 1992-2022. Cinq études menées entre 1989 et 2005 remplissaient les critères pour être prises en compte dans l'analyse, en utilisant un indice de masse corporelle supérieur ou égal à $30 \mathrm{~kg} / \mathrm{m}^{2}$ pour définir l'obésité. Les projections ont révélé que la prévalence globale de l'obésité devrait augmenter, passant de 12 \% en 1992 à 41 \% d'ici 2022 chez l'homme, et de $21 \%$ à 78 \% chez la femme. Les projections de la prévalence étaient nettement plus élevées chez la femme que chez l'homme, notamment dans les tranches d'âge 35-44, 45-54 et 55-64 ans. Des stratégies nationales efficaces sont requises pour freiner ou enrayer l'augmentation prévue de la prévalence de l'obésité.

${ }^{7}$ General Directorate of Health Affairs at Al-Ahssa Region, Ministry of Health, Saudi Arabia (Correspondence to A.J. Al-Quwaidhi: aal-qwidi@moh. gov.sa). ${ }^{2}$ Institute of Health and Society, University of Newcastle, Newcastle upon Tyne, United Kingdom. ${ }^{3}$ Population Health Research Centre, St George's University of London, London, United Kingdom. ${ }^{4}$ Institute of Psychology, Health and Society, University of Liverpool, Liverpool, United Kingdom.

Received: 29/12/13; accepted: 10/06/14 


\section{Introduction}

Obesity is defined as the "accumulation of adipose tissue to excess and to an extent that impairs both physical and psychosocial health and well-being" (1). It is associated with various health problems, including type 2 diabetes, cardiovascular disease and cancer (2). Obesity is currently a major public health problem in most countries, particularly low- and middle-income countries. The Global Burden of Disease (GBD) study in 2008 estimated that around 500 million adults were obese (3). In the Eastern Mediterranean Region (EMR), the problem of obesity is mounting. According to the GBD study, the region of North Africa and the Middle East had the 7th highest prevalence of obesity in men (among the $21 \mathrm{GBD}$ regions of the world), and the 2 nd highest in women between 1980 and 2008 (3). In men, the estimated prevalence of obesity in the region increased substantially from $<10 \%$ in 1980 to $20-30 \%$ in 2008 and in women it increased from $10-20 \%$ to $30-40 \%$ over the same period (3).

Saudi Arabia is one of the largest and wealthiest countries in the EMR. It has witnessed extensive socioeconomic development in recent decades, accompanied by changes in the population standards of living toward a high-calorie dietary pattern and sedentary lifestyle (4). In the published nationwide surveys, obesity prevalence among adults in Saudi Arabia showed a progressive increase from $22 \%$ in $1990-1993$ (5) to $36 \%$ in 2005 (6). Currently, there are no studies providing data on the trends and future projections of the prevalence of adult obesity in Saudi Arabia. These data are needed by health policy-makers in Saudi Arabia in order to set policies for proper planning and allocation of resources to combat this growing public health problem. This study aimed to explore the trends in the prevalence of adult obesity in Saudi Arabia, stratified by sex and age groups, and to provide reasonable future projections up to 2022.

\section{Methods}

\section{Study design}

This study was a secondary analysis of published data, in which a number of assumptions were applied to estimate the trends and projections in the prevalence of adult obesity in Saudi Arabia over the period 1992-2022.

\section{Review of national surveys on obesity prevalence}

We carried out a comprehensive literature review of studies on the prevalence of obesity in Saudi Arabia by searching the Medline database for publications from 1980 to week 46 of 2013, using different terms for titles and keywords. Examples of terms used were: "obesity", "fatness", "overweight", "body weight", "weight", "central obesity", "abdominal obesity", "body mass index", "BMI", "waist circumference", "Saudi Arabia", "prevalence", etc. The reference lists of relevant articles were checked to identify other potential studies. The inclusion criteria for studies were the following: a nationwide, population-based survey covering all regions of Saudi Arabia; multistage, stratified random sampling technique; both men and women included; prevalence of obesity reported; and definition of obesity clearly stated. The exclusion criteria were studies that: covered a subnational sample of the population (e.g. covered only one region of the country, or only one sex); or used self-measured weight and height. Duplicate papers, which reported data from the same study in different age ranges, were also excluded and only the most recent paper that reported the prevalence for adults was selected.

The review resulted in a total of 141 potential articles. After review of the titles and abstracts and full articles, 5 studies (5-9) were found eligible for inclusion (Table 1).These surveys were conducted between 1989 and 2005, and used body mass index $($ BMI $) \geq 30 \mathrm{~kg} / \mathrm{m}^{2}$ to define obesity. All these studies used good sampling techniques with multistage, stratified random sampling of households in all regions of Saudi Arabia, with probability proportionate to the population size of each region. They covered large nationwide sample sizes of households and included both sexes. The reported response rates in these studies were excellent (> 90\% in most studies). Anthropometric data (height and weight) were collected using standardized and calibrated tools by trained teams. Thus, the studied samples were judged likely to be reliable and representative of the total Saudi population.

\section{Adjustment of data from the selected studies}

Four of the selected surveys (5,7-9) were carried out over a period range; e.g. 1990-1993 and 1995-2000, and their results were reported in different age group intervals, while 1 study (5) provided only age-specific prevalence rates (no sex-specific rates). Therefore, we made some explicit and reasonable assumptions to make the age group intervals consistent for all studies and to obtain single-year prevalence rates. Other assumptions were made to obtain sex- and age-specific rates for all studies.

First, it was assumed that the reported prevalences applied roughly to the midpoint of the period range. For instance, the study of Al-Nozha et al. (7) was conducted over the period 1995-2000, so we assumed that the results applied to 1997 . Similarly, the results of Warsy \& El-Hazmi (9), conducted during 1992-95, were assumed to apply to 1993, and those of Al-Nuaim et al. (5), carried out during 1990-1993, were assumed to apply to 1992.

Secondly, the age group bands of studies were adjusted to 10 -year intervals, consistent with those in the most recent World Health Organization (WHO) STEPwise study (6). Thus, the age range 25 to 64 years, which was covered by most of the studies, was analysed in intervals $25-34,35-44,45-54$ and 55-64 years. For other studies, our assumptions took into account the 


\begin{tabular}{|c|c|c|c|c|c|c|c|c|}
\hline \multirow[t]{2}{*}{ Study (ref.) } & \multirow{2}{*}{$\begin{array}{l}\text { Data } \\
\text { collection } \\
\text { period }\end{array}$} & \multicolumn{3}{|c|}{ Sample size (No.) } & \multirow{2}{*}{$\begin{array}{c}\text { Age groups } \\
\text { studied (years) }\end{array}$} & \multicolumn{3}{|c|}{ Obesity prevalence (\%) } \\
\hline & & Men & Women & Total & & Men & Women & Total \\
\hline \multirow[t]{7}{*}{ WHO STEPwise (6) } & 2005 & 2244 & 2345 & 4589 & All (15-64) & 28.3 & 43.8 & 36.2 \\
\hline & & - & - & - & All (25-64) & $(31.5)$ & $(50.4)$ & $(41.2)$ \\
\hline & & - & - & - & $15-24$ & 17.8 & 19.6 & - \\
\hline & & - & - & - & $25-34$ & 27.1 & 39.5 & - \\
\hline & & - & - & - & $35-44$ & 34.5 & 54.7 & - \\
\hline & & - & - & - & $45-54$ & 32.9 & 58.8 & - \\
\hline & & - & - & - & $55-64$ & 31.0 & 53.2 & - \\
\hline \multirow[t]{5}{*}{ Al-Nozha et al. ( 7 ) } & 1995-2000 & - & - & 17232 & All (30-70) & 26.4 & 44.0 & 35.6 \\
\hline & & - & - & - & $30-39$ & 25.2 & 40.2 & - \\
\hline & & - & - & - & $40-49$ & 30.3 & 50.2 & - \\
\hline & & - & - & - & $50-59$ & 27.8 & 45.9 & - \\
\hline & & - & - & - & $60-70$ & 22.1 & 39.0 & - \\
\hline \multirow[t]{5}{*}{ Osman \& Al-Nozha (8) } & 1989-1994 & 2673 & 3590 & 6253 & All $(\geq 18)$ & 15.6 & 24.9 & 20.8 \\
\hline & & - & - & - & $18-<21$ & 9.0 & 16.5 & - \\
\hline & & - & - & - & $21-<31$ & 10.4 & 22.1 & - \\
\hline & & - & - & - & $31-<40$ & 20.7 & 32.7 & - \\
\hline & & - & - & - & $\geq 40$ & 20.8 & 33.2 & - \\
\hline \multirow[t]{6}{*}{ Warsy \& El-Hazmi (9) } & 1992-1995 & 6646 & 9064 & 15710 & All $(>14)$ & 13.1 & 20.3 & 15.8 \\
\hline & & - & - & - & 14-19 & 4.7 & 4.5 & - \\
\hline & & - & - & - & $20-29$ & 9.1 & 13.2 & - \\
\hline & & - & - & - & $30-39$ & 15.9 & 26.9 & - \\
\hline & & - & - & - & $40-49$ & 19.2 & 36.0 & - \\
\hline & & - & - & - & $50-59$ & 16.4 & 28.7 & - \\
\hline \multirow[t]{5}{*}{ Al-Nuaim et al. (5) } & 1990-1993 & 5407 & 5244 & 10651 & All $(\geq 20)$ & 17.8 & 26.6 & 22.1 \\
\hline & & - & - & - & $20-29$ & - & - & 14.7 \\
\hline & & - & - & - & $30-39$ & - & - & 24.8 \\
\hline & & - & - & - & $40-49$ & - & - & 33.2 \\
\hline & & - & - & - & $50-59$ & - & - & 26.3 \\
\hline
\end{tabular}

- = data not available or not relevant.

overlap between the reported age groups and those set for this study. For example, in Al-Nozha et al.'s study (7), the prevalence of obesity in the age group 35-44 years was assumed to be the average of the reported prevalences for those aged $30-39$ and $40-49$ years, while the prevalence in the age group 45-54 years was assumed to be equivalent to the average of that reported for age groups 40-49 and 50-59 years. Similarly, in the study of Warsy \& El-Hazmi (9), the prevalence for the age group 25-34 years was assumed to be the average of age groups 20-29 and 30-39 years, for
35-44 years it was assumed to be the average of age groups 30-39 and 40-49 years, while for 55-64 years it was set to be equivalent to the age group $\geq 50$ years.

Thirdly, an estimated sex ratio was applied to data from Al-Nuaim et al.'s study (5), which reported only the age-specific prevalence. The sex ratio of prevalence was calculated for each age group in the study of Warsy \& ElHazmi (9) and these age-specific ratios were applied to Al-Nuaim et al.'s data. The explicit assumption was that such sex ratios were unlikely to differ substantially between these 2 studies.
Finally, the results of Osman \& Al-Nozha's study (8) were excluded, because it included relatively younger age groups (18-20, 21-30, 31-40 and $\geq 40$ years) and it was not possible to obtain age groups consistent with the other studies.

\section{Trends in obesity prevalence from 1992 to 2005}

After adjustment of the data from the selected studies we presented the estimated prevalence rates for individual years (1992, 1993, 1997 and 2005). A linear interpolation approach was 
used to fill in the gaps of the missing years. The average obesity prevalence were calculated between each 2 time points, assuming a linear increase in prevalence. For example, to calculate the prevalence of obesity in 1994 the formula: $(3 \times a 1+a 2) / 4$ was used, where $a 1$ was the prevalence in 1993 and $\alpha 2$ the prevalence in 1997. Similarly, for 1995 the formula: $(2 \times a 1+2 \times a 2)$ /4 was used, while for year 1996 we used the formula: $(\alpha 1+3 \times a 2) / 4$ and so on. These formula calculations were applied to each single population age group for each individual year.

\section{Projections of adult obesity prevalence from 2006 onwards}

Due to the inherent uncertainty of any future projections of obesity prevalence, we made an uncomplicated but plausible assumption to estimate the projections among adults in Saudi Arabia. We assumed that the obesity trends would show a linear increasing trend from 2006 onwards with the same observed annual rate of increase during the period 1992-2005. The annual rate of increase in prevalence was estimated by dividing the net difference in prevalence for each sex and age group during the time period by the duration (number of years) of the same time period. So the annual rate of increase during 1992-2005 was calculated as: [(prevalence in 2005) (prevalence in 1992)]/13.
The decision to apply a linear increasing trend in obesity prevalence was justified by observing the same linear trend from the existing local data (5-9) during 1992-2005 in almost all age groups of both sexes. Furthermore, the assumption was supported by the recent estimates of trends in mean BMI by the GBD study (3), which also showed a linear increasing trend in mean BMI of both sexes in Saudi Arabia across the years 1980, 1990, 2000 and 2008

The overall annual prevalence for each sex was calculated by dividing the weighted average of the prevalence rates of all age groups by the size of Saudi population aged 25-64 years (men versus women), as obtained from the population statistics published by the Central Department of Statistics and Information (10).

\section{Results}

\section{Trends in obesity prevalence from 1992-2005}

Table 2 summarizes the age- and sexspecific prevalence of obesity among adults aged 25-64 years in Saudi Arabia over the period 1992-2005, after applying the assumptions described earlier to the data from the 5 studies. In men, the prevalence increased from around $10.1 \%$ to $27.1 \%$ in those aged $25-34$ years, and from $12.9 \%$ to $31.0 \%$ in the age group 55-64 years. In comparison, the prevalence rates among women were higher across all age groups. For example, obesity prevalence increased from $16.1 \%$ to $39.5 \%$ in those aged 25-34 years, and from $22.8 \%$ to $53.2 \%$ in the age group 55-64 years

The estimated average annual rates of increase for each sex and age group are also shown in Table 2 . The highest rate of increase was $1.9 \%$ for men aged $35-44$ years, and $3.1 \%$ for women aged 45-54 years. On the other hand, the smallest rate of increase was around $1.5 \%$ for men aged $25-34$ years, and $2.1 \%$ for women in the same age group.

\section{Projections of adult obesity prevalence from 2006 onwards}

Table 3 presents the trends and future projections of age- and sex-specific prevalence of obesity from 1992-2022, assuming a linear increasing trend. Over the 30-year period from 1992-2022, the prevalence of obesity was projected to increase markedly (by more than $200 \%$ ) in all age groups of men and women aged 25-64 years. However, women had much higher projected prevalence rates than men, particularly in the age groups $35-44,45-54$ and 55-64 years. It can be noted that the increase in obesity prevalence for both sexes was steeper between 1992 and 1997 than that of the other years.

\begin{tabular}{|c|c|c|c|c|c|c|c|c|c|}
\hline \multirow[t]{2}{*}{ Study (ref.) } & \multirow{2}{*}{$\begin{array}{c}\text { Year/ } \\
\text { midpoint } \\
\text { of period }\end{array}$} & \multicolumn{4}{|c|}{ Men } & \multicolumn{4}{|c|}{ Women } \\
\hline & & $25-34$ yrs & $35-44$ yrs & $45-54 \mathrm{yrs}$ & $55-64 \mathrm{yrs}$ & $25-34$ yrs & $35-44$ yrs & $45-54$ yrs & $55-64$ yrs \\
\hline \multicolumn{10}{|l|}{ Obesity prevalence (\%) } \\
\hline Al-Nuaim et al. (5) & 1992 & 10.1 & 14.0 & 14.2 & 12.9 & 16.1 & 25.1 & 25.8 & 22.8 \\
\hline Warsy \& El-Hazmi (9) & 1993 & 12.5 & 17.6 & 17.8 & 16.4 & 20.1 & 31.5 & 32.4 & 28.7 \\
\hline Al-Nozha et al. (7) & 1997 & 25.2 & 27.8 & 29.1 & 25.0 & 40.2 & 45.2 & 48.1 & 42.5 \\
\hline WHO STEPwise (6) & 2005 & 27.1 & 34.5 & 32.9 & 31.0 & 39.5 & 54.7 & 58.8 & 53.2 \\
\hline $\begin{array}{l}\text { Average annual rate of } \\
\text { increase in obesity (\%) }\end{array}$ & - & 1.5 & 1.9 & 1.7 & 1.7 & 2.1 & 2.8 & 3.1 & 2.8 \\
\hline
\end{tabular}




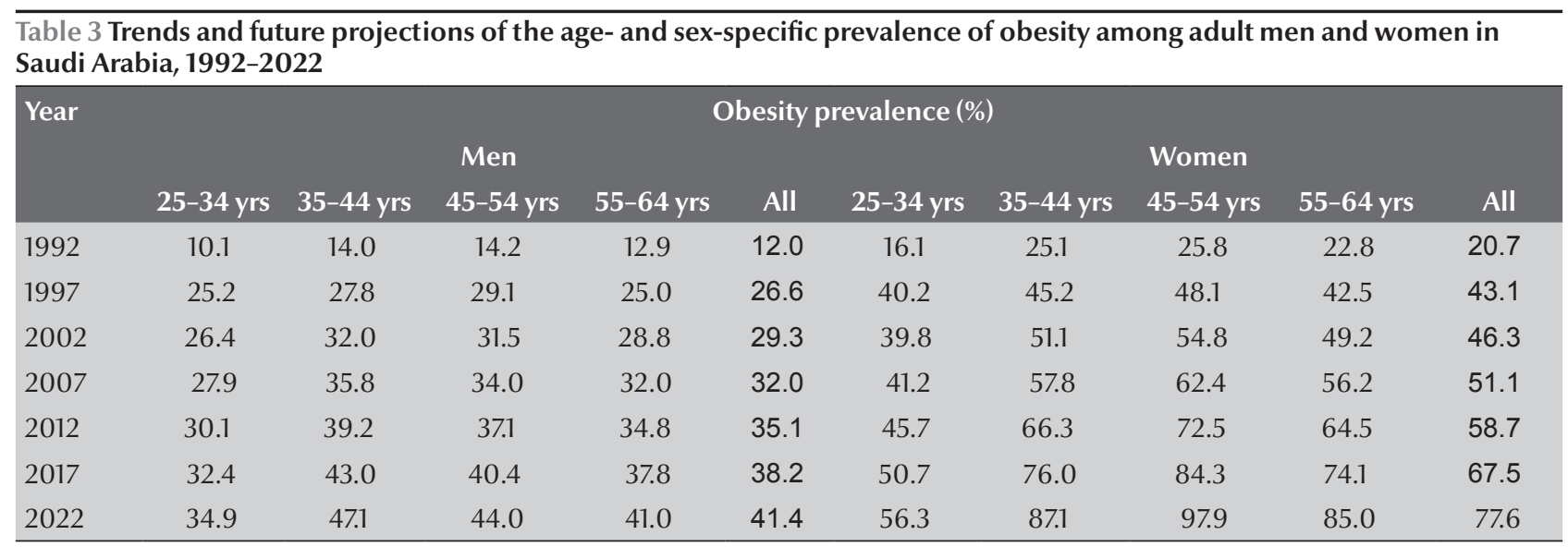

Figure 1 illustrates the trends and future projections of the overall obesity prevalence among adult men and women in Saudi Arabia during 1992-2022. The overall prevalence of obesity was projected to increase from around $12 \%$ in 1992 to $41 \%$ by 2022 in men, and from $21 \%$ to $78 \%$ in women.

\section{Discussion}

This study presents the trends in adult obesity prevalence in Saudi Arabia and provides reasonable projections of the likely future levels. The prevalence data used in this study were derived from large nationwide population-based surveys that were representative of the Saudi population. These surveys showed that the prevalence of obesity increased markedly across all age groups of adult men and women between 1992 and 2005. We projected that obesity prevalence will continue rising in both sexes up to 2022, which appears to correlate with the increasing trend in energy intake of the Saudi population. It has been estimated by the United Nations Food and Agriculture
Organization that the total food supply in Saudi Arabia increased from 2797 to $3076 \mathrm{kcal} /$ capita per day between 1992 and 2009 (11).

The observed and projected prevalence rates of obesity were much higher across all age groups of adult women than those of men, although the relative increases in prevalence between 1992 and 2022 were extremely high (> $200 \%$ ) in both sexes. This is generally consistent with data published by the WHO Regional Office for the Eastern Mediterranean, which clearly showed a significantly higher prevalence of

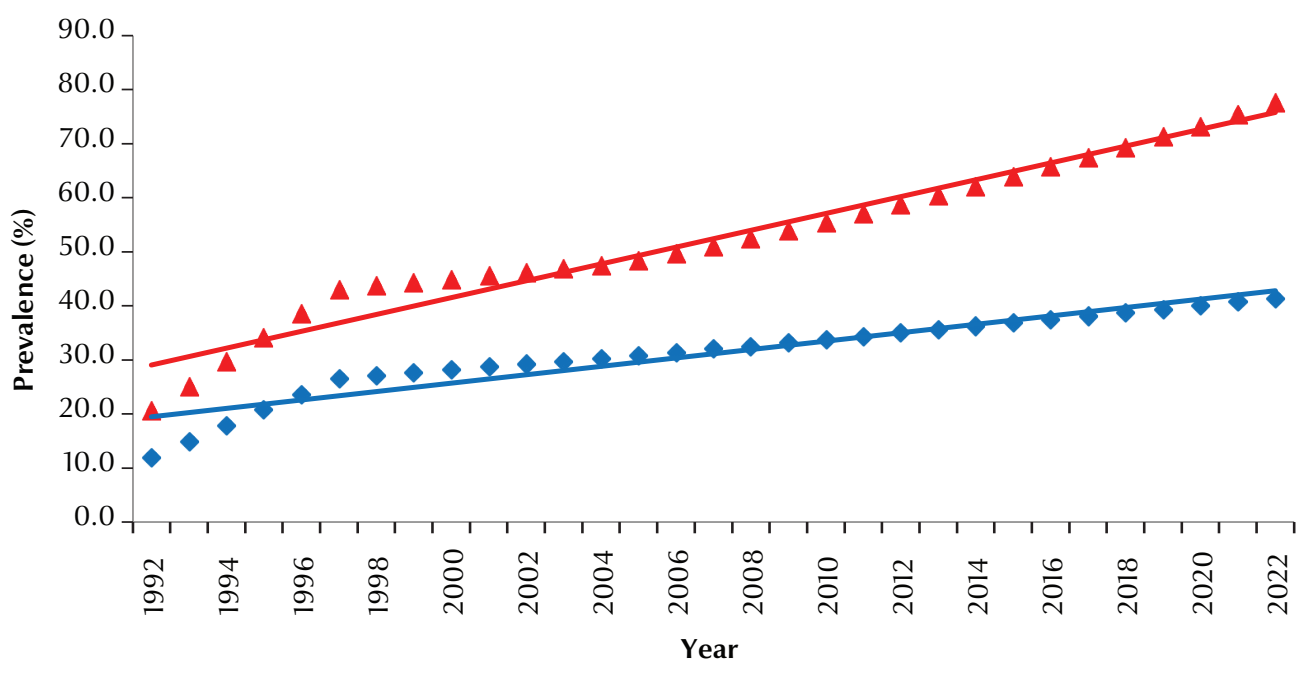

$\checkmark$ Obesity prevalence (men)

A Obesity prevalence (women)

Linear trendline (men)

Linear trendline (women) 
obesity in adult women in almost all countries of the Region $(12,13)$.

The large sex differences in the prevalence of obesity in Saudi Arabia (and other EMR countries) have been attributed mainly to the greater sedentary lifestyle patterns among women than men. For instance, the reported prevalence of sufficient physical activity (at least 150 minutes per week) in the Gulf Cooperation Council (GCC) countries is significantly lower among adult women (26.3-28.4\%) than men (39.0-42.1\%) (14). These prevalence rates of sufficient physical activity are much lower than those reported in developed countries, such as Australia (15) and the United States of America (16), as well as neighbouring EMR countries such as Egypt (17). This can be explained by the unique cultural context of the GCC countries, which poses constraints on the physical activity of women. For most women, social conventions lead to restrictions on their activities outside the home, limited opportunities to attend gyms and health clubs, as well as a high dependency on automobiles and domestic maids.

The assumptions used in this study are consistent with similar assumptions used and validated in previous projection studies in different settings. For example, the assumption of the period midpoint for data sources that cover multiple years was used by the most recent GBD study (3). In addition, the sex ratio assumption was used by the recent study of the International Diabetes Federation to estimate the global prevalence of diabetes (18). In that study, if data were not available for one sex, prevalence ratios from other sources were used. Furthermore, applying linear increasing trends in prevalence of obesity were used by some previous studies, such as that of Zaninotto et al., who calculated the rate of increase in adult obesity in the United Kingdom between 1993 and 2004 and assumed that such a rate will remain constant until 2012 (19). However, it is important to mention that the results of our study represent future predictions that are conditional on the assumptions made and should not be considered as scientific facts.

There are some published studies which have provided useful information on the trends in obesity prevalence and BMI in Saudi Arabia (20-22). However, none of these studies attempted to make future projections of obesity prevalence. In addition, some of these studies explored the trends in children and adolescents (not adults), and covered only particular regions of the country. In contrast, our study has the advantage of offering future projections of adult obesity prevalence at the national level and not only of exploring the trends from existing data. This is particularly important for public health planning, setting preventive strategies and allocation of resources.

However, our study has some potential limitations. First, we projected the future obesity prevalence in Saudi Arabia assuming a linear increasing trend with the same rate of increase as that observed in national surveys between 1992 and 2005. Nevertheless, these surveys were not carried out by the same group/organization and therefore variations in the reported results across years would be expected. For instance, the rate of increase in obesity prevalence between 1992 and 1997 was much higher than that of the other years. If that trend were correct, it would be consistent with recently emerging evidence that the total prevalence of adult obesity (BMI $\geq 30 \mathrm{~kg} / \mathrm{m}^{2}$ ) in the United States (23) and several European (24) and Asian (25) countries has started to show stability or slowing/levelling off in the last 10-13 years. The causes of such levelling off in the global obesity prevalence trends in recent years are not completely understood, and are mentioned for further analysis (25). In Saudi Arabia, there are no sufficient periodic surveys that reliably measure the rate of that potential slowing in obesity prevalence trends. Hence, in the absence of such data, we used an uncomplicated assumption to project the future prevalence (linear increase). Our assumption was based mainly on the observed trends (5-9) and the recent GBD estimates of BMI trends in Saudi Arabia (3), which showed linear increasing trends in both men and women between 1980 and 2008 . However, it is important to mention that our main aim was not to provide precise projections of the adult obesity prevalence in Saudi Arabia, but to predict the future picture if the currently observed trends continued.

Secondly, obesity was defined using only the BMI measurement in all national surveys utilized in this study. Therefore, some cases of central obesity in which the BMI is $<30 \mathrm{~kg} / \mathrm{m}^{2}$ might be missed, leading to underestimates of the true burden of obesity in Saudi Arabia.

Thirdly, we did not estimate the trends and projections of obesity for those aged $\geq 65$ years, as data for these age groups from the existing national surveys were scarce and patchy.

Nevertheless, the results from this study have important implications for public health policy planning in Saudi Arabia. The substantial increases in the forecasted obesity prevalence among adult men and women over the next decade necessitate urgent implementation (or follow up) of relevant, effective strategies to tackle these rising levels $(26,27)$

\section{Conclusion}

Adult obesity is a major public health problem in Saudi Arabia, and if the currently observed trends continue, the levels are expected to rise substantially over the next decade. Effective national strategies are needed to reduce or halt the projected rise in obesity prevalence.

Competing interests: None declared. 
1. James PT. Obesity: the worldwide epidemic. Clin Dermatol. 2004 Jul-Aug;22(4):276-80. PMID:15475226

2. Obesity and overweight. Fact sheet no. 311. Geneva: World Health Organization; 2014 (http://www.who.int/mediacentre/factsheets/fs311/en/, accessed 20 July 2014).

3. Finucane MM, Stevens GA, Cowan MJ, Danaei G, Lin JK, Paciorek CJ, et al.; Global Burden of Metabolic Risk Factors of Chronic Diseases Collaborating Group (Body Mass Index). National, regional, and global trends in body-mass index since 1980: systematic analysis of health examination surveys and epidemiological studies with 960 country-years and 9.1 million participants. Lancet. 2011 Feb 12;377(9765):557-67. PMID:21295846

4. Health system profile, Saudi Arabia. Cairo: World Health Organization, Regional Office for the Eastern Mediterranean; 2006 (http://gis.emro.who.int/HealthSystemObservatory/ PDF/Saudi Arabia/Full Profile.pdf, accessed 20 July 2014).

5. Al-Nuaim AA, Bamgboye EA, Al-Rubeaan KA, Al-Mazrou Y. Overweight and obesity in Saudi Arabian adult population, role of socio-demographic variables. J Community Health. 1997 Jun;22(3):211-23. PMID:9178120

6. WHO STEPwise approach to NCD surveillance. Countryspecific standard report, Saudi Arabia 2004. Riyadh: Ministry of Health, Saudi Arabia, and World Health Organization; 2005 www.who.int/chp/steps/2005_SaudiArabia_STEPS_Report_ EN.pdf, accessed 20 July 2014).

7. Al-Nozha MM, Al-Mazrou YY, Al-Maatouq MA, Arafah MR, Khalil MZ, Khan NB, et al. Obesity in Saudi Arabia. Saudi Med J. 2005 May;26(5):824-9. PMID:15951877

8. Osman AK, Al-Nozha MM. Risk factors of coronary artery disease in different regions of Saudi Arabia. East Mediterr Health J. 2000 Mar-May;6(2-3):465-74

9. Warsy AS, El-Hazmi MA. Diabetes mellitus, hypertension and obesity-common multifactorial disorders in Saudis. East Mediterr Health J. 1999 Nov;5(6):1236-42. PMID:11924118

10. Latest statistical releases [Internet]. Riyadh: Central Department of Statistics and Information (http://www.cdsi.gov.sa/ english/, accessed 20 July 2014).

11. Food balance sheet, Saudi Arabia. FAOSTAT [Internet]. Rome: Food and Agriculture Organization of the United Nations http://faostat.fao.org/site/368/default.aspx\#ancor, accessed 20 July 2014).

12. Khatib O. Noncommunicable diseases: risk factors and regional strategies for prevention and care. East Mediterr Health J. 2004 Nov;10(6):778-88. PMID:16335764

13. Regional strategy on nutrition 2010-2019 and Plan of action Cairo: World Health Organization, Regional Office for the Eastern Mediterranean; 2011 (http://www.emro.who.int/dsaf/ dsa1230.pdf, accessed 20 July 2014).

14. Mabry RM, Reeves MM, Eakin EG, Owen N. Evidence of physical activity participation among men and women in the countries of the Gulf cooperation council: a review. Obes Rev. 2010 Jun;11(6):457-64. PMID:19793376
15. Physical activity patterns of Australian adults. Canberra: Australian Institute of Health and Welfare; 2000 (http://www.aihw. gov.au/WorkArea/DownloadAsset.aspx?id=6442454841, accessed 14 August 2014).

16. Prevalence of regular physical activity among adults-United States, 2001 and 2005. MMWR Morb Mortal Wkly Rep. 2007;56:1209-12. PMID:18030281

17. National survey on chronic disease and their risk factors, for age group 15-65, Egypt, 2005-2006. STEPS fact sheet. Cairo: Ministry of Health and Population; 2005 (http://www.who. int/chp/steps/STEPS_FactSheet_Egypt.pdf, accessed 14 August 2014).

18. Guariguata L, Whiting D, Weil C, Unwin N. The International Diabetes Federation diabetes atlas methodology for estimating global and national prevalence of diabetes in adults. Diabetes Res Clin Pract. 2011 Dec;94(3):322-32. PMID:22100977

19. Zaninotto P, Head J, Stamatakis E, Wardle H, MindellJ. Trends in obesity among adults in England from 1993 to 2004 by age and social class and projections of prevalence to 2012. J Epidemiol Community Health. 2009 Feb;63(2):140-6. PMID:19074182

20. Ng SW, Zaghloul S, Ali HI, Harrison G, Popkin BM. The prevalence and trends of overweight, obesity and nutrition-related non-communicable diseases in the Arabian Gulf States. Obes Rev. 2011 Jan;12(1):1-13. PMID:20546144

21. Al-Hazzaa HM. Rising trends in BMI of Saudi adolescents: evidence from three national cross sectional studies. Asia Pac J Clin Nutr. 2007;16(3):462-6. PMID:17704028

22. Al-Hazzaa HM. Prevalence and trends in obesity among school boys in Central Saudi Arabia between 1988 and 2005. Saudi Med J. 2007 Oct;28(10):1569-74. PMID:17914521

23. Flegal KM, Carroll MD, Kit BK, Ogden CL. Prevalence of obesity and trends in the distribution of body mass index among US adults, 1999-2010. JAMA. 2012 Feb 1;307(5):491-7. PMID:22253363

24. National Obesity Observatory [Internet]. London: Public Health England (http://www.noo.org.uk, accessed 20 July 2014).

25. Rokholm B, Baker JL, Sørensen TIA. The levelling off of the obesity epidemic since the year 1999 £a review of evidence and perspectives. Obes Rev. 2010 Dec;11(12):835-46. PMID:20973911

26. Khatib OMN. Guidelines for the prevention, management and care of diabetes mellitus. Cairo: World Health Organization, Regional Office for the Eastern Mediterranean; 2006 (EMRO Technical Publication Series No. 32).

27. Supporting the implementation of the United Nations Resolution (UNR) on diabetes (61/225) in Middle East and North Africa. International Diabetes Federation (IDF) Middle East and North Africa (MENA) regional meeting, Alexandria, Egypt, 18 April 2009. Brussels: International Diabetes Federation; 2009 (https://www.idf.org/sites/default/files/ attachments/IDF-MENA-Action-Plan-141009.pdf, accessed 20 July 2014). 